\title{
The Motility of Some Clostridium Species
}

\author{
By T. N. STANBRIDGE* AND N. W. PRESTON \\ Department of Bacteriology and Virology, University of Manchester
}

(Accepted for publication 22 August 1968)

\begin{abstract}
SUMMARY
The capillary tube method is found to be better than the hanging drop method for examining the motility of cultures of clostridia in different media. In the capillary tube, Clostridium butyricum and $C$. sporogenes moved away from air and oxygen gas-phases at the meniscus. Reasons for the failure to show this negative aerotaxis in $C$. septicum are discussed. The motility of $C$. sporogenes was activated by $\mathrm{L}$-arginine.
\end{abstract}

\section{INTRODUCTION}

By comparison with the extensive literature devoted to the study of factors which affect the motility of aerobic bacteria, the motility of anaerobes has seldom been mentioned. The present editions of standard bacteriological textbooks which mention methods for demonstrating the motility of anaerobes state that the capillary tube is superior to either the hanging drop or plain slide and coverslip methods (Willis, 1960; Topley and Wilson's Principles, 1964; Cruickshank, I965); no comparative study appears to have been published. Beijerinck (I893) reported that in his slide and coverslip preparations anaerobic bacteria formed densely populated central zones and less densely populated peripheral zones and that motility persisted longer in the central zones, where he assumed that the oxygen tension was less. Smith (I960) stated that the motility of Clostridium septicum persisted longer in the presence of oxygen than did that of $C$. oedematiens. Aerotaxis was first recorded by Engelmann (I88I) who described the aggregation of 'Bacillus termino' in the neighbourhood of an oxygen source and used this organism as an indicator of oxygen production by photosynthetic mechanisms of plants, isolated plant cells, algae and chloroplasts. Further reports by Engelmann (1882a, $b, 1894)$ mentioned a variety of bacteria on which oxygen had a chemotactic effect. Jennings \& Crosby (I90I) studied the reactions of Spirillum volutans and $S$. undula near illuminated algae: away from the algae the organisms moved randomly and with no indication that their direction was influenced by the focus of oxygen production; organisms entering the zone near the algae were unable to leave, for whenever they reached the edge of the zone their direction of motion was reversed. This indirect experimental system was used also by Baracchini \& Sherris (1959) to show that $C$. histolyticum, $C$. septicum and $C$. sporogenes moved away from an oxygen source. There appears to be no other recorded attempt to show negative aerotaxis by obligate anaerobic organisms; this subject seemed worthy of examination.

* Present address: Public Health Laboratory, 121 A Osmaston Road, Derby. 


\section{METHODS}

Culture of organisms. The three Clostridium strains used were obtained from the Manchester University Collection of Bacteria (MUCOB). They were C. sporogenes (MUCOB 383), C. septicum (MUCOB I58) and C. butyricum (MUCOB I62). Each organism was maintained by subculture on horse-blood agar in Petri dishes incubated anaerobically (McIntosh and Fildes jar), with duplicate plates incubated aerobically to test for contamination by aerobes. Liquid medium was inoculated from a I-day colony on a blood agar plate. Solid and liquid cultures were incubated at $36^{\circ}$ in a McIntosh and Fildes jar.

Preparation of samples of cultures for microscopical examination. Flat capillary tubes, at least $100 \mathrm{~mm}$. long, were prepared from glass tubing by a modification of the method of Wright \& Colebrook (I92I). These were filled by capillary action from the deepest parts of the liquid culture to be examined. An air space was left at the end not immersed in the culture, and this end occluded by the forefinger while the other end was sealed in a Bunsen flame. The tube was then reversed and the air space sealed in the flame. Oxygen or nitrogen was passed from a cylinder with a reducing valve through a wash bottle containing water and then through a very fine capillary tube which was introduced into an opened end of a capillary tube containing a culture; the gas was allowed to play continuously on the meniscus of the culture. Measurements of distances relative to the meniscus were made with the vernier scale on the microscope stage.

Staining. Flagella were stained by a modification of Gray's method (Preston \& Maitland, 1952).

\section{RESULTS}

\section{Methods of examining for motility: comparison of} hanging-drop and capillary-tube methods

Organisms grown in liquid medium. Clostridia grown anaerobically for $20 \mathrm{hr}$ at $36^{\circ}$ in four different media were examined for motility by the hanging-drop and capillarytube methods. An attempt was made to assess the proportion of motile organisms in each preparation; the results are recorded in Table I. Motility was affected by the medium in which the organism was grown, and a medium suitable for showing active motility of one strain was not necessarily satisfactory for another. The motility of Clostridium butyricum was seen best in digest broth; Robertson cooked meat medium was better for $C$. septicum and $C$. sporogenes. In general the motility of these three organisms was more active and persisted longer in a capillary tube than in a hanging drop, even when the latter preparations were sealed with petroleum jelly.

The character of the motility in the three organisms differed. Clostridium butyricum showed a variety of kinds, the commonest being a cork-screw motion in which the leading end of a bacillus described smaller rotational movements than the trailing end. Other bacilli showed rapid jerky movements, whilst some progressed steadily in straight lines. C. butyricum showed less frequent changes of direction than C. septicum or $C$. sporogenes. The slow undulating movement of $C$. septicum most nearly resembled the classical description of motility in the genus Clostridium, which is said to be 'slow and stately'. Clostridium sporogenes showed rapid jerky movements with frequent changes in direction. 
Organisms grown on solid medium. Cultures of the three organisms were grown anaerobically for $20 \mathrm{hr}$ at $36^{\circ}$ on blood agar and the growth was suspended in water, Sorensen's phosphate buffer ( $\mathrm{pH} 7$ ), peptone water or digest broth. Each suspension was non-motile by both capillary tube and hanging drop techniques. But by staining it was shown that all three species had produced flagella on the solid medium. No difference in the morphology of the flagella was seen as between bacteria grown on solid medium and those grown in liquid medium. Perhaps the loss of motility resulted from exposure to air during removal of the cultures from the anaerobic jar and transfer of the surface growth to a suspending medium. No attempt was made to do these operations in an oxygen-free atmosphere.

Table I. Motility of Clostridium species grown in four different culture media: comparison of hanging drop and capillary tube methods of examination

Samples of cultures grown anaerobically for $20 \mathrm{hr}$ at $36^{\circ}$ were examined by the hanging drop (HD) and capillary tube (CT) techniques at various times $(t)$ after sampling. The proportion of motile bacilli seen in each preparation was graded: - , no motile bacilli seen; \pm , motile bacilli constituted less than $5 \%$ of the population;,+ 5 to $15 \%$ of bacilli motile;,++ 15 to $40 \%$ motile;,+++ 40 to $100 \%$ motile.

\begin{tabular}{|c|c|c|c|c|c|c|c|c|c|c|c|c|c|}
\hline \multirow[b]{2}{*}{ nin.) } & \multirow[b]{2}{*}{$\ldots$} & \multicolumn{4}{|c|}{ C. butyricum } & \multicolumn{4}{|c|}{ C. septicum } & \multicolumn{4}{|c|}{ C. sporogenes } \\
\hline & & 0 & 15 & 30 & 60 & 0 & 15 & 30 & 60 & 0 & 15 & 30 & 60 \\
\hline $\begin{array}{l}\text { bertson } \\
\text { joked meat } \\
\text { edium }\end{array}$ & $\underset{\mathrm{CT}}{\text { HD }}$ & + & $\begin{array}{l} \pm \\
+\end{array}$ & $\overline{+}$ & $\overline{+}$ & $\begin{array}{l}+t \\
+t\end{array}$ & $\begin{array}{l}++ \\
++\end{array}$ & + & + & $\begin{array}{l}+++ \\
+++\end{array}$ & $\begin{array}{c}++ \\
+++\end{array}$ & $\begin{array}{c}++ \\
+++\end{array}$ & $\begin{array}{c}+ \\
++\end{array}$ \\
\hline zest broth & $\underset{\mathrm{CT}}{\mathrm{HD}}$ & $\begin{array}{c}++ \\
+++\end{array}$ & $\begin{array}{c}+ \\
++\end{array}$ & $+\overline{+}+$ & $\bar{t}+$ & $\overline{ \pm}$ & $\overline{ \pm}$ & \pm & $\overline{ \pm}$ & $\begin{array}{l}++ \\
++\end{array}$ & $\begin{array}{l}++ \\
++\end{array}$ & $\begin{array}{l}++ \\
++\end{array}$ & + \\
\hline $\begin{array}{l}\text { tone } \\
\text { ater* }\end{array}$ & $\underset{\mathrm{CT}}{\mathrm{HD}}$ & - & $\overline{-}$ & - & - & $\bar{t}$ & $\bar{t}$ & $\overline{-}$ & $\overline{ \pm}$ & $\begin{array}{l}- \\
-\end{array}$ & - & $\begin{array}{l}- \\
-\end{array}$ & - \\
\hline $\begin{array}{l}\text { trient } \\
\text { oth }+ \\
\text { ioglycollic } \\
\text { id } \\
\text { I } \%, w / v)\end{array}$ & $\underset{\mathrm{CT}}{\mathrm{HD}}$ & $\overline{-}$ & - & - & - & $\begin{array}{l}+ \\
+\end{array}$ & $\begin{array}{l}+ \\
+\end{array}$ & $\begin{array}{l}+ \\
+\end{array}$ & \pm & $\begin{array}{l}++ \\
++\end{array}$ & $\begin{array}{c}++ \\
+\end{array}$ & $\begin{array}{l}+ \\
+\end{array}$ & $\stackrel{+}{++}$ \\
\hline
\end{tabular}

\section{Influence of incubation temperature on motility}

Triplicate cultures of Clostridium butyricum in digest broth, and of C. septicum and C. sporogenes in Robertson cooked meat medium, were incubated for $20 \mathrm{hr}$ at $36^{\circ}$, $30^{\circ}$ and $25^{\circ}$. They were examined for motility by the capillary tube method. No significant difference in the type or duration of motility of the cultures grown at the three temperatures was observed.

\section{Examination of the motility of three clostridia by the capillary tube method}

The previous experiments showed that, as far as motility was concerned, the best results were obtained when the capillary tube method was used for the examination of digest broth cultures of Clostridium butyricum, and Robertson cooked meat cultures of $C$. septicum and $C$. sporogenes, incubated at $36^{\circ}$. These conditions were used for the examination of these organisms, in cultures incubated for $18 \mathrm{hr}$.

Clostridium butyricum. The motility of this organism was different in different culture media. Sometimes it was sluggish, although usually more than $50 \%$ of the organ- 
isms were motile; on other occasions it was much more active. In preparations showing sluggish motility the bacilli lost their motility first in the region near the meniscus and this zone of non-motile bacilli gradually extended along the capillary tube (see Table 2). All motility throughout the tube ceased within $48 \mathrm{hr}$, and the final sediment

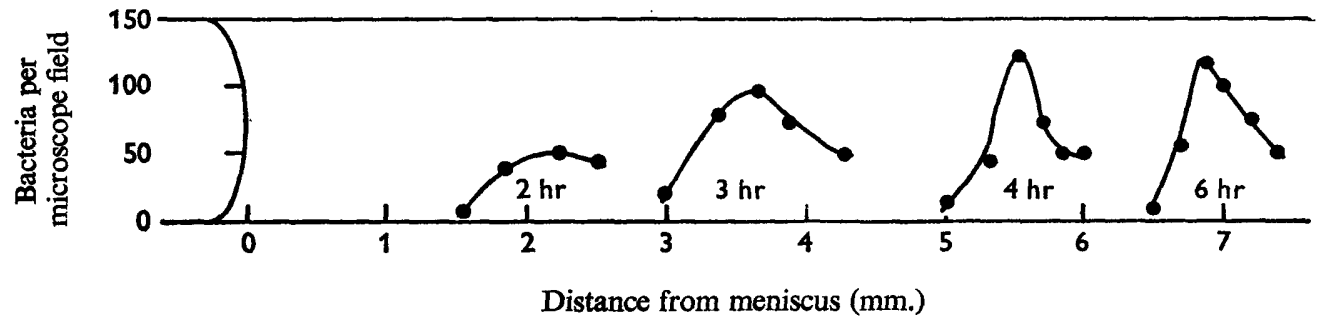

Fig. I. Diagrammatic representation of the formation and movement of a dense band of Clostridium butyricum in a capillary tube, due to negative aerotaxis.

\title{
Table 2. Progressive loss of motility of Clostridium butyricum when exposed to air
}

\begin{abstract}
A sample from a culture of $C$. butyricum, grown anaerobically for $\mathrm{i} 8 \mathrm{hr}$ in digest broth at $36^{\circ}$, was transferred to a capillary tube and examined microscopically. Motility ceased near the gas/liquid meniscus; the distance to which this zone of non-motile organisms extended from the meniscus was measured at intervals $(t)$ after transfer of the culture to the tube. Two experiments were made $(A, B)$.
\end{abstract}

\begin{tabular}{ccc} 
Time $(t)$ (min) & $\begin{array}{c}\text { Distance (mm) from meniscus } \\
\text { to nearest motile organisms }\end{array}$ \\
\cline { 2 - 3 } 60 & $3 \cdot 8$ & Expt. A. \\
140 & $4 \cdot 6$ & $4 \cdot 1$ \\
200 & $5 \cdot 0$ & $5 \cdot 3$ \\
230 & $5 \cdot 4$ & $5 \cdot 6$ \\
320 & $6 \cdot 0$ & $5 \cdot 9$ \\
380 & $6 \cdot 3$ & $6 \cdot 2$ \\
1440 & $7 \cdot 1$ & $6 \cdot 7$ \\
2880 & $7 \cdot 2$ & $8 \cdot 0$ \\
& & $7 \cdot 5$
\end{tabular}

of bacilli appeared uniform throughout the tube. With cultures showing more active motility, a similar progressive loss of motility was observed, beginning near the gas/ liquid meniscus and proceeding along the capillary. The time relationships were like those shown in Table 2, but now a dense band of motile organisms could be seen between the zones of motile and non-motile organisms. This band became progressively more dense and more easily recognizable, but of no greater width, as it receded from the meniscus. An attempt to give some idea of the size and density of this band, and its speed of travel, was made by counting at intervals the number of organisms visible in the field of the microscope (see Fig. I).

Clostridium septicum. The motility of this organism was always very low. Cultures never showed more than $40 \%$ of motile bacilli, usually only about $15 \%$. Loss of motility occurred first in the region of the gas/liquid meniscus and gradually extended along the tube. In a typical series of observations, the zone of non-motile bacilli extended $2 \mathrm{~mm}$. from the meniscus at $\mathrm{I} \mathrm{hr}, 4$ to $5 \mathrm{~mm}$. at $4 \mathrm{hr}$, and 8 to $9 \mathrm{~mm}$. at $8 \mathrm{hr}$; farther along the tube, no progressive extension of the zone of non-motile bacilli was 
seen, but all the organisms became non-motile by $24 \mathrm{hr}$. The sedimented organisms were then uniformly distributed along the tube.

Clostridium sporogenes. The motile organisms appeared to recede from the gas/ liquid meniscus. Within $2 \mathrm{hr}$ a band of increased concentration of organisms was seen which gradually moved from the meniscus until at $6 \mathrm{hr}$ it became stationary about $2.5 \mathrm{~mm}$. from it. The width of the band was about $0.7 \mathrm{~mm}$., the edge nearer the meniscus being very sharply defined. Between this well-defined edge and the meniscus, there were only very few sedimented bacilli, the difference in concentration between this region and the remainder of the tube being very obvious. Motility throughout the tube ceased within $48 \mathrm{hr}$.

Table 3. Movement of Clostridium butyricum and $C$. sporogenes away from oxygen, in capillary tube

\begin{tabular}{|c|c|c|c|}
\hline \multirow{3}{*}{$\begin{array}{l}\text { Time } \\
\text { (min.) }\end{array}$} & \multicolumn{3}{|c|}{$\begin{array}{l}\text { Distance (mm.) from meniscus to dense band } \\
\text { of organisms }\end{array}$} \\
\hline & \multicolumn{2}{|c|}{ C. butyricum } & \multirow[t]{2}{*}{ C. sporogenes } \\
\hline & Expt. I & Expt. 2 & \\
\hline 20 & $2 \cdot 4$ & 2.5 & - \\
\hline $\begin{array}{l}45 \\
60\end{array}$ & $\begin{array}{l}5.4 \\
6 \cdot 1\end{array}$ & $\begin{array}{l}5 \cdot 7 \\
6 \cdot 2\end{array}$ & $1 \cdot 3$ \\
\hline 85 & $7 \cdot 2$ & $7 \cdot 0$ & 4.5 \\
\hline 105 & $7 \cdot 9$ & $7 \cdot 8$ & - \\
\hline 120 & - & - & $5 \cdot 7$ \\
\hline 140 & 8.7 & $8 \cdot 7$ & - \\
\hline 170 & $9 \cdot 3$ & $9 \cdot \mathrm{I}$ & $6 \cdot 7$ \\
\hline 200 & $9 \cdot 9$ & $9 \cdot 7$ & $6 \cdot 9$ \\
\hline 230 & 10.6 & 10.0 & - \\
\hline 260 & 10.9 & 10.4 & $6 \cdot 9$ \\
\hline 305 & $11 \cdot 7$ & $I I \cdot I$ & 6.9 \\
\hline 365 & 12.4 & $11 \cdot 9$ & - \\
\hline 1440 & $13 \cdot 2$ & - & - \\
\hline
\end{tabular}

\section{Influence of oxygen on motility}

Clostridium butyricum. When the gas-space near the meniscus was continuously flushed with oxygen, a dense band of organisms developed as it had done when the space was filled with air. The band was thinner and better defined, and it moved more quickly and to a greater distance than when the gas was air. As the band moved, the organisms between it and the gas/liquid meniscus became non-motile. The band persisted for some hours but gradually became less distinct and dispersed after about $24 \mathrm{hr}$. The results of duplicate experiments are shown in Table 3.

Clostridium septicum. The result with oxygen was similar to that with air except that the loss of motility progressed more rapidly and extended 8 to $9 \mathrm{~mm}$. from the meniscus after only $3 \mathrm{hr}$. A further extension of the zone of non-motile bacilli was not obvious; motility ceased throughout the tube within 24 to $48 \mathrm{hr}$. At no time was a band of increased concentration of bacilli seen; the bacilli appeared to sediment uniformly throughout the tube.

Clostridium sporogenes. As with C. butyricum, loss of motility occurred more rapidly and extended farther when oxygen replaced air at the gas/liquid meniscus. A band of bacilli became visible within $45 \mathrm{~min}$., moved rapidly from the meniscus and became 
stationary at $6.9 \mathrm{~mm}$. from the meniscus after about $3 \mathrm{hr}$ (Table 3). Beyond the band, motility persisted for about $24 \mathrm{hr}$, after which the bacilli sedimented throughout the tube. The sediment was less dense in the region extending $6.9 \mathrm{~mm}$. from the meniscus than in the rest of the tube.

\section{Influence of nitrogen on motility}

When the gas space in the capillary was flushed with a stream of nitrogen, all three species remained uniformly motile. Progressive loss of motility extending gradually from the meniscus was not observed nor was a dense band of organisms formed. Motility persisted throughout the tube for several hours and then became uniformly sluggish and ceased after about $48 \mathrm{hr}$.

\section{Influence of medium in which organisms were suspended}

Motility of cultures of Clostridium butyricum and C. sporogenes in digest broth, and of $C$. septicum in Robertson cooked meat medium, was observed at $20 \mathrm{hr}$; the cultures were then centrifuged at $2500 \mathrm{rev} . / \mathrm{min}$. for $10 \mathrm{~min}$. In separate experiments the deposits were washed once or three times in glass-distilled water, peptone water or digest broth. After re-suspension in the same media, they were examined for motility by the capillary tube technique. In no case were any motile bacilli of $C$. butyricum or $C$. septicum seen; but even after washing three times, $C$. sporogenes was still motile, for more than $8 \mathrm{hr}$ in peptone water and in digest broth, but only for $10 \mathrm{~min}$. in distilled water. Stained preparations of each organism, before and after washing, showed no morphological change in the flagella. It seems likely that the loss of motility of $C$. butyricum and $C$. septicum on washing was a reflexion of extreme sensitivity to oxygen. Each organism remained motile after centrifugation when resuspended in the supernatant fluid, but when this was removed and the bacilli were exposed to air they became non-motile.

\section{Table 4. Duration of motility of Clostridium sporogenes related to initial concentration of arginine}

$\begin{array}{llrllll}\text { Concentration of arginine }(\mu \mathrm{M}) & \ldots & 100 & 50 & 25 & 12 \cdot 5 & 6 \cdot 25 \\ \begin{array}{l}\text { Duration of motility after } \\ \text { organisms in water control had }\end{array} & 81 & 40 & 22 & 13 & 4 \\ \text { become non-motile (min.) } & & & & & \end{array}$

Effect of amino acids. Since a washed suspension of Clostridium sporogenes showed motile organisms much longer in peptone water or digest broth than in distilled water, it seemed likely that motility might depend on the presence of amino acids. C. sporogenes was therefore incubated anaerobically for $20 \mathrm{hr}$ in digest broth, washed three times in distilled water, the third centrifuged deposit was re-suspended in a few drops of distilled water and a drop of this suspension added to $0.5 \mathrm{ml}$. of a $10 \mathrm{mM}$ solution of each of the following amino acids: L-arginine, L-asparagine, L-aspartic acid, DLglutamine, glycine, DL-methionine, DL-serine, DL-threonine, DL-tryptophane; as a control, a drop of the suspension was added to $0.5 \mathrm{ml}$. distilled water. Motility persisted for only Io to $15 \mathrm{~min}$. in the water-control and in eight of the nine amino acids, but with L-arginine the organisms remained motile for more than $8 \mathrm{hr}$. 
Concentration of arginine. One drop of a washed suspension of Clostridium sporogenes, prepared as described above, was added to $0.5 \mathrm{ml}$. of a solution of arginine at concentrations of 100 to $6 \mu \mathrm{M}$. The duration of motility, persisting after organisms in a water-control had become non-motile, was proportional to the concentration of arginine in the solution, over the range tested (Table 4).

\section{DISCUSSION}

The motility of each of the organisms studied (Clostridium butyricum, C. septicum, C. sporogenes) was inhibited by air, so that the hanging-drop method of examination was not very satisfactory except for the least oxygen-sensitive of the three, namely C. sporogenes. By the capillary tube method, the relative sensitivities of the three species could be examined in more detail. All three became non-motile near the gas/ liquid meniscus, the loss of motility occurring most rapidly and extending farthest from the meniscus with $C$. septicum, and being least rapid and least extensive with C. sporogenes. The active component of the air appeared to be oxygen, since when air was replaced with nitrogen no inhibition of motility occurred near the meniscus, but when air was replaced with oxygen, motility at a given distance from the meniscus ceased more rapidly than with air and the organisms became non-motile for a greater distance from the meniscus. Moreover there was evidence, with $C$. sporogenes and C. butyricum, of negative aerotaxis-movement of organisms away from the air/liquid interface. A dense band of organisms developed between the non-motile bacilli near the meniscus and the motile bacilli in the rest of the tube, and this band gradually moved farther away from the meniscus. The concentration of organisms between meniscus and band was less than that on the other side of the band, suggesting that the motile members of the bacterial population were escaping from the adverse effect of a high concentration of oxygen by moving away from the meniscus. The fact that the band of $C$. butyricum moved farther than that of $C$. sporogenes suggested that it was less tolerant of oxygen. C. septicum showed neither a zone near the meniscus where the density of organisms was less than that in the rest of the tube nor a dense band of organisms. Perhaps this organism does not have a negative aerotactic response; or perhaps its motility was so slow that it was overwhelmed by the increasing oxygen concentration as air diffused inwards from the meniscus, and the organism was rendered non-motile before it could escape from the inhibitory zone.

Clostridium sporogenes remained motile for a short period after washing and resuspending in distilled water, probably because of residual traces of essential metabolites from the culture medium. This motility was prolonged by L-arginine, but not by any of eight other amino acids tested. Sherris, Preston \& Shoesmith (1957) showed that arginine alone, of 20 amino acids they tested, prolonged the motility of a pseudomonad under relatively anaerobic conditions; and it is possible that the motility of C. sporogenes too is dependent on energy liberated by the metabolism of arginine, used directly or indirectly through the mediation of energy-rich phosphate bonds, as suggested by Sherris et al. (1957) for their pseudomonad. This involves the assumption that adenosine triphosphate (ATP) is the immediate source of energy. However, whilst De Robertis \& Peluffo (I95I) claimed that ATP enhanced the motility of Proteus vulgaris, and De Robertis \& Franchi (1952) reported that bacterial flagella contracted in the presence of ATP, Barlow \& Blum (1952) found no ATPase activity 
in flagellar preparations, nor did addition of ATP to a suspension of flagella cause any change in the shape or in the state of aggregation of the flagella. Another mechanism by which energy might be provided for the motility of $C$. sporogenes is through a Stickland reaction in which arginine served as a hydrogen acceptor (Woods, 1936). A second amino acid would be required as a reductant, and this might be difficult to reconcile with the observation that arginine added alone was effective. However, it is possible that an amino acid present in the cell pool, or a product of arginine metabolism, might act as reductant.

\section{REFERENCES}

Baracchini, O. \& Sherris, J. C. (1959). The chemotactic effect of oxygen on bacteria. J. Path. Bact. 77, 565 .

Barlow, G. H. \& Blum, J. J. (1952). On the 'contractility' of bacterial flagella. Science, N.Y. r16, 572.

BEIJERINCK, M. W. (I 893). Über Atmungsfiguren beweglicher Bakterien. Zentbl. Bakt. ParasitKde r4, 827.

CRUICKSHank, R. (1965). Medical Microbiology, i Ith ed., p. 308. Edinburgh: Livingstone.

DE Robertis, E. \& FRANCHI, C. M. (1952). Macromolecular structure of the contractile protein of bacterial flagella. J. appl. Phys. 23, I6I.

De Robertis, E. \& Peluffo, C. A. (I95I). Chemical stimulation and inhibition of bacterial motility studied with a new method. Proc. Soc. exp. Biol. Med. 78, 584 .

EngelmanN, T. W. (188I). Neue Methode zur Untersuchung der Sauerstoffausscheidung pflanzlicher und thierischer Organismen. Bot. Ztg 39, 44I.

Engelmann, T. W. (1882a). Zur Biologie der Schizomyceten. Bot. Ztg 40, 32 I.

Engelmann, T. W. (1882 b). Zur Biologie der Schizomyceten. Bot. Ztg 40, 337.

EngelmanN, T. W. (1894). Die Erscheinungsweise der Sauerstoffausscheidung chromophyllhaltiger Zellen im Licht bei Anwendung der Bacterienmethode. Arch. Anat. Physiol. 57, 375.

JENNINGS, H. S. \& CROSBY, J. H. (I90I). Studies on reactions to stimuli in unicellular organisms. VII. The manner in which bacteria react to stimuli, especially to chemical stimuli. Am. J. Physiol. 6, 3 I.

Preston, N. W. \& Martland, H. B. (1952). The influence of temperature on the motility of Pasteurella pseudotuberculosis. J. gen. Microbiol. 7, I 7.

Sherris, J. C., Preston, N. W. \& Shoesmith, J. G. (I957). The influence of oxygen and arginine on the motility of a strain of Pseudomonas sp. J. gen. Microbiol. I6, 86.

SmIth, L. DE S. (1960). Introduction to the Pathogenic Anaerobes, p. 135. Chicago: University Press. Topley and Wilson's Principles of Bacteriology and Immunity (1964). 5th ed. Ed. by G. S. Wilson and A. A. Miles, p. 1047, London: Arnold.

Willis, A. T. (1960). Anaerobic Bacteriology in Clinical Medicine, p. 40. London: Butterworth.

Woods, D. D. (1936). Studies in the metabolism of the strict anaerobes (genus Clostridium). V. Further experiments on the coupled reactions between pairs of amino-acids induced by $C$. sporogenes. Biochem. J. 30, 1934.

Wright, A. E. \& Colebrook, L. (1921). Technique of the Teat and Capillary Glass Tube, p. 22. London: Constable. 